\title{
Experimental study on flow distribution in micro backflow combustor
}

\author{
Junli Yu, Chungang Qu*, Xuan Wang \\ Civil Aviation University of China, College of Aeronautical Engineering, Tianjin 300300, China
}

Corresponding Author Email: pqbird@sina.com

https://doi.org/10.18280/ijht.360330

Received: 18 December 2017

Accepted: 15 May 2018

\section{Keywords:}

flow distribution, backflow combustor, plugging method, thermistor, micro jet engine

\begin{abstract}
Based on the measurement principle of plugging method and the changes in the relationship between temperature and resistance of thermistor, this study explores the flow distribution of backflow combustor of a micro jet engine. The experimental results show that with the increase of the inlet flow of the combustion, the flow distribution of different airflow channels on the wall of the flame tube will change in the micro backflow combustor. When the combustor's inlet flow is relatively large, the flow distribution approaches to the value calculated by the area method. At the same time, the experimental results show that this method is suitable for the study of flow distribution.
\end{abstract}

\section{INTRODUCTION}

Along with the development of unmanned aerial vehicles (UAVs), more and more attention has been paid to the study of micro jet engines [1-3]. The micro jet engine of the order of $10 \mathrm{~cm}$ has been favored due to the advantages of a few parts, simple structure, low manufacturing cost and wide application range. There are many kinds of engine products of this order at abroad, and there are many institutions to study it in China. Because of the size limitation of a micro jet engine, the structure of the combustor is small, so the flame stable structure of large jet engine is not suitable for micro combustor. In the micro engine of this size, a direct-current or backflow annular combustor is used, and the fuel is atomized by an evaporating pipe. The jet flow hole and the evaporating pipe cooperate to form a backflow vortex to stabilize the combustion. Due to the small size of the combustor and the short residence time of the fuel in the combustor, it is necessary to have a reasonable flow field structure to achieve high combustion efficiency. The flow distribution of various airflow channels on the flame tube plays a very important role to realize the proper flow field structure. These airflow channels include evaporating pipes and various jet flow holes through which the airflow entering the combustor forms a backflow vortex, completes combustion, mixes with the fuel gas, and cools the flame tube. In order to realize these functions, the flow distribution of various airflow channels should be well grasped in the design of flame tube. Determination of airflow distribution mainly adopts calculation and test methods, and may be based on experience when the design experience is rich [4-9]. However, when the design experience is insufficient, it is mainly determined by tests. In particular, in the preliminary design of the new combustor, the data are accumulated through the tests in order to modify the design scheme better.

This study measures the flow distribution of a micro backflow combustor is, analyzes the change of the flow distribution of the combustor with the inlet flow, and compares the flow distribution with that calculated by the area method.
In order to adapt to the structure of small combustor, thermistor is used for measurement based on the principle of flow distribution plugging method [10]. By using the relationship between resistance and temperature of thermistor, the flow of each airflow channel can be obtained according to the plugging method. The thermistor is small and sensitive, and is suitable for the flow distribution measurement of micro combustor. The test method is studied through experiments, which provides a test method for better testing the flow distribution of micro combustor.

\section{TEST MODEL}

A micro jet engine on the order of ten $\mathrm{cm}$ has a limited size on its combustor. In order to better stabilize combustion in such small space, a backflow combustor is designed. The structure is shown in Figure 1. The inner axial length of the combustor flame tube is $69 \mathrm{~mm}$, the radial length is $24 \mathrm{~mm}$, and the outer ring diameter of the flame tube is $117 \mathrm{~mm}$. Air enters the combustor from the channel between the left flame tube and the outer wall, as shown in Figure 1, and the incoming airflows around the flame tube, enters the flame tube from a row of evaporating pipes and five rows of jet flow holes on the wall of the flame tube, and finally flows out from the left flame tube outlet in Figure 1. The positions of the evaporating pipe and the jet flow hole are shown in Figure 2 where 8 evaporating pipes are arranged at position 1 with the inner diameter of $8 \mathrm{~mm}$. The airflow enters the turning direction of 45 degrees, and then turns back at the outlet to the axial direction. At positions 2 and 4 are two rows of 5-mm-diameter jet flow holes. Each row has 16 holes. These two rows of holes have a relatively large aperture, which is the main jet flow hole on the inner and outer rings of the flame tube. On the right half of the flame tube at the outlet of the evaporating pipe is the combustion area. The main jet flow hole and the evaporating pipe cooperate to form a backflow area to stabilize combustion, and the large aperture makes the jet depth large, and also plays the role of mixing fuel gas. In position 3 are 32 jet flow holes 
with an internal diameter of $2.5 \mathrm{~mm}$, and this row of holes are for afterburning in the combustion zone. In position 5 , there are 24 jet flow holes with a diameter of $3 \mathrm{~mm}$. In position 6 are 24 jet flow holes with a diameter of $2 \mathrm{~mm}$. These two rows of holes act mainly in admixture with the fuel gas. The structure of the flame tube is simple, and the number of jet flow holes is small so as to concentrate the airflow to form the flow field structure.

In the test, a $1 / 2$ semi-annular combustor model is used. The inlet of the combustor is connected with a contraction transition section and the outlet is directly discharged to the atmosphere. The total flow at the inlet of the combustor is measured by a float flowmeter, and the flow is controlled by a valve in the gas path by using an air pump as a gas source.

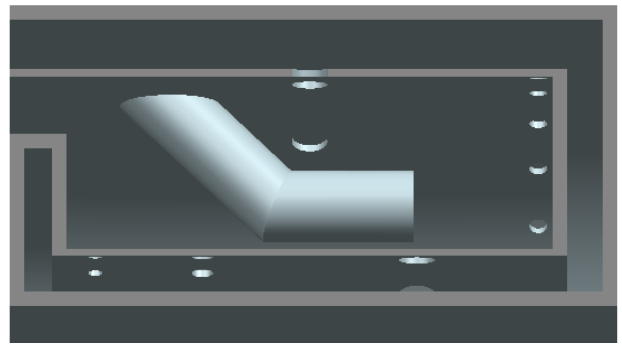

Figure 1. Structure diagram of backflow combustor

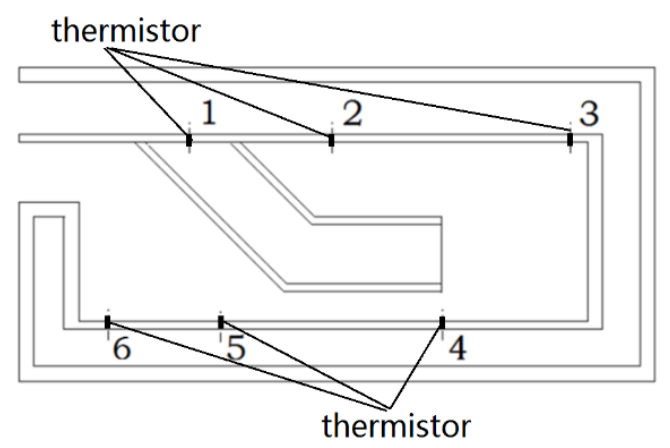

Figure 2. Schematic diagram of airflow channel of flame tube

\section{MEASUREMENT PRINCIPLE OF TEST}

A commonly used method for measuring the flow distribution of combustor is the plugging method which is also called the flow characteristic curve method. The whole measurement process is divided into two steps. In the first step, a row of holes are open and the remaining holes are plugged. Pressure taps are arranged on the inner and outer walls of the holes, and the pressure difference is measured when the airflows through the row of holes. The change in the inlet flow can obtain the relation curve between the flow and the pressure difference, namely the flow characteristic curve. In the same way, a flow characteristic curve for each row of holes can be obtained. In the second step, all the pressure taps of all the holes are kept unchanged and all the holes are open. The pressure difference value of each row of holes under each total flow is measured. The pressure difference value is compared with the flow characteristic curve of each row of holes measured in the first step to obtain the flow through the holes at this time. Similarly, the flow distribution of each row of holes with different total flow can be obtained. The suitability of this test can be judged by whether the sum of the flow of each row is equal to the total flow.

Many pressure taps need to be arranged when the flow distribution of the combustor is measured by the plugging method. For the micro combustor with limited size, the pressure tapping equipment is not easy to satisfy. Therefore, based on the above measuring principle, a small and sensitive thermistor is used to measure the flow distribution of the combustor. When the thermistor passes through a relatively large current, its own temperature rises and the temperature change will change its own resistance value. The thermistor is put at the outlet of the hole, namely in the flame tube, which has a certain distance from the hole. The airflow through the hole will cool the thermistor. When the heat generated by the resistance is equal to the heat carried by the airflow [11], the temperature of the resistance is no longer changed and the resistance value remains unchanged. The thermistor and a sampling resistor are connected in series in a certain circuit and powered by a constant voltage power supply. When the resistance value of the thermistor changes, the voltage of the corresponding sampling resistor will change accordingly so that a corresponding voltage value can be obtained. When the flow of the holes changes, the airflow velocity changes and the heat of the thermistor carried away by the airflow also changes. The temperature of the thermistor changes to a new value, and the voltage value also changes accordingly. In the first step, the corresponding curve of the flow and voltage of each row of holes are measured by plugging, namely the flow characteristic curve of each row of holes in the plugging method. In the second step, when each row of holes is open and the position of the thermistor is unchanged, the voltage value of each row of holes is measured. The flow value of each row of holes can be obtained by comparing it with the flow and voltage relation curve of each row of holes obtained in the first step.

In the test, PT1000 thermistor whose size is $1 \mathrm{~mm} \times 2 \mathrm{~mm} \times 2$ $\mathrm{mm}$ is adopted with high sensitivity and good recovery. It is supported by two thin pin wires. In the airflow direction with the smallest windward area, the thermistor is placed at the outlet of each hole, and the thermistor of measuring evaporating pipe is placed in the evaporating pipe with a distance from the inlet. The pin of the thermistor is connected to the external circuit of the combustor through a thin metal wire and the voltage is measured with a millivolt voltmeter. A thermocouple is installed in the center of the inlet of the combustor to measure the inlet airflow temperature.

\section{TEST RESULTS AND ANALYSIS}

In the test, the total flow at the inlet of the combustor changes from $32 \mathrm{~m}^{3} / \mathrm{h}$ to $144 \mathrm{~m}^{3} / \mathrm{h}$, and is converted into an inlet airflow speed of about $6.7 \mathrm{~m} / \mathrm{s}$ to $30 \mathrm{~m} / \mathrm{s}$. The thermistor is sensitive to temperature, so it is necessary to control the temperature of the airflow during each test. In each test, the temperature is measured with a thermocouple at the inlet of the combustor, and the temperature of the airflow at the inlet is controlled within $33 \pm 0.5^{\circ} \mathrm{C}$, and the repeatability of repeated measurements is good.

According to the measurement principle of the plugging method, the relationship between the flow of each row of holes and the voltage is measured, as shown in Figure 3. The horizontal axis is the voltage percentage which is obtained by comparing the measured voltage with the reference voltage, 
and the vertical axis is the airflow through each row of holes. The number 1 to 6 represents each row of holes indicated in Figure 2. Then, open all the holes and keep the position of the thermistor unchanged, and measure the flow-voltage relationship of each row of holes, as shown in Figure 4. Finally, in order to obtain the flow of each row of holes when all the holes are open, the data in Figure 3 are fitted by a cubic polynomial, and the corresponding flow value is found by the voltage value of each measurement point in Figure 4 into the fitting curve of Figure 3 so as to obtain the flow of each row of holes under different inlet flow of the combustor, as shown in Figure 5. The horizontal axis is the total airflow at the inlet of the combustor and the vertical axis is the airflow at each row of holes.
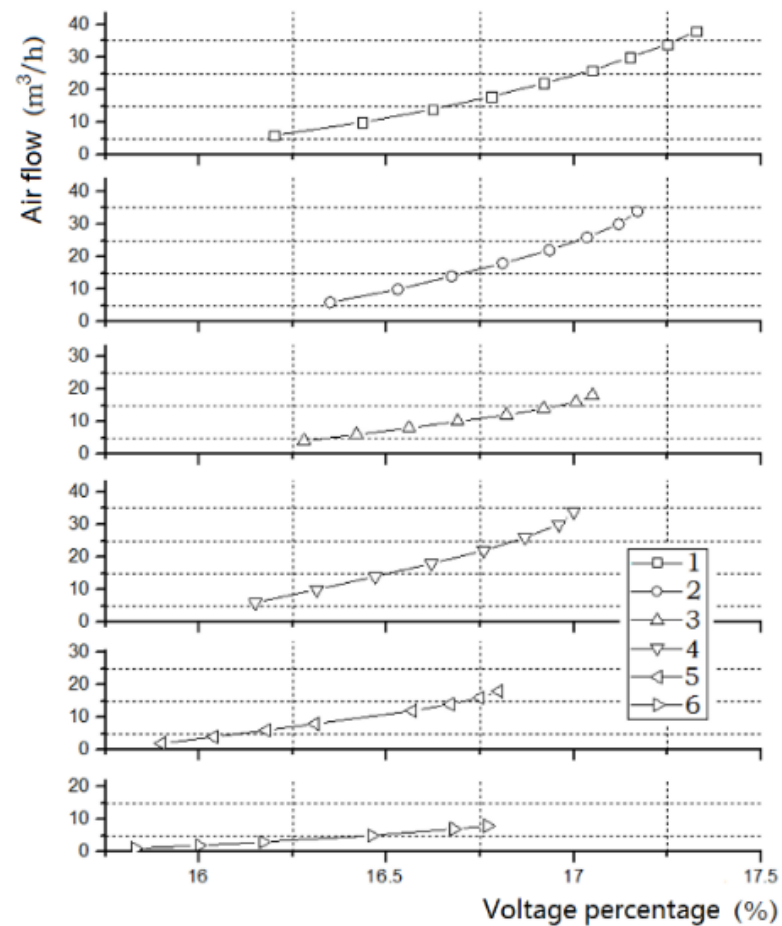

Figure 3. Relationship between flow and voltage when plugging

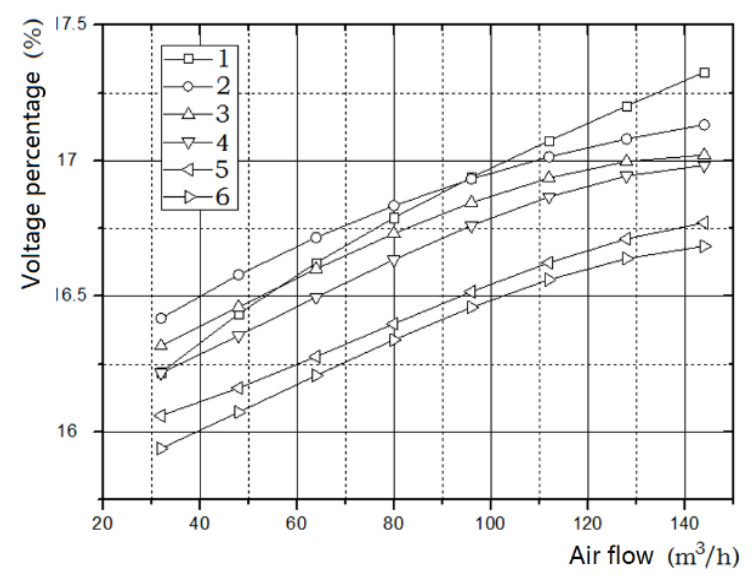

Figure 4. Relationship between flow and voltage when holes are open

In the test, the position of the thermistor is kept unchanged so that the flow field can be ensured to be consistent in twostep measurement by the plugging method. In addition, each test should ensure that the inlet air temperature is consistent because the thermistor is sensitive to temperature and the temperature of the incoming flow will cause measurement errors. The accuracy of the test data is verified according to the matching degree between the total flow and the total flow of each row of holes. Through calculation, the relative difference between the total flow and the total flow of each row of holes under different total flow is less than $\pm 5 \%$.

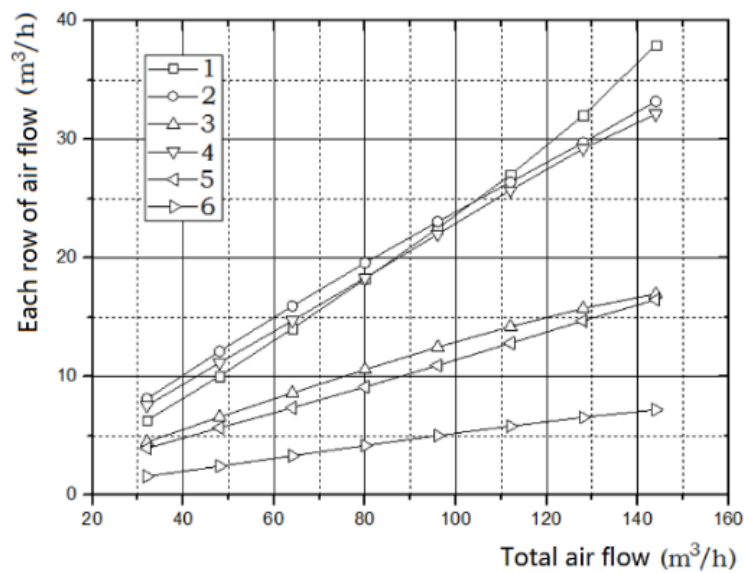

Figure 5. Flow of each row of holes

As can be seen from Figure 5, the flow of each row of holes increases with the increase of the inlet flow, and the flow of the first row of holes, namely, the evaporating pipe, increases most significantly. Figure 6 shows the percentage of total flow for each row of holes to the total flow at different total flow. It can be seen from Figure 6 that the percentage change of the evaporating pipe flow is the largest as the total flow increases mainly because the flow resistance of the evaporating pipe is different from that of the circular hole on the wall surface of the common flame tube. With the increase of the percentage of flow in the evaporating pipe, the percentage of flow in the second, third and fourth rows of holes decreases obviously while the percentage of flow in the fifth and sixth rows of holes changes very little.

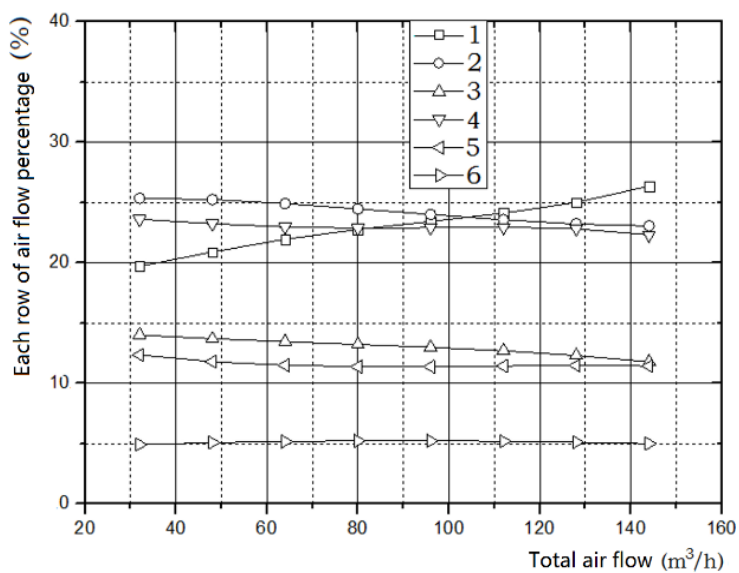

Figure 6. Percentage of flow of each row of holes

The area method is the simplest method when there is not enough experience to estimate the flow distribution of the combustor. This method uses the ratio of the area of each row of holes to the total area to determine the ratio of the flow of each row of holes to the total flow under the assumption that the flow coefficients of each row of holes are equal and the gas 
density is the same. According to the area method, when the total flow changes, the pressure difference on both sides of holes changes accordingly, so the flow distribution of each hole keeps unchanged.

Figure 7 is a comparison of flow distribution of area conversion and test measurement, and the dotted line shows the flow of each row of holes calculated by the area method, and the values are plotted on the dotted line. As can be seen from Figure 7, the flow distribution of each row of holes is close to that calculated by the area method as the total flow increases. The flow distribution of the three rows of holes on the outer ring of the flame tube, namely the evaporating pipe and the second and third rows of holes, changes a lot, while that of the three rows of holes on the inner ring of the flame tube, namely the fourth, fifth and sixth rows of holes changes a little. This change is related to the structure of the backflow combustor. As shown in Figure 2, the flame tube is wrapped around the flame tube to form a revolving airflow channel, and the airflow entering the combustor enters the channel and sequentially enters the flame tube through the rows of holes 1 , $2,3,4,5$ and 6 . When the total flow is small, the pressure difference on both sides of the hole is small. The flow resistance of the first row of evaporating pipe is large, so the deviation from the flow percentage calculated by the area method is large. The decrease of the flow distribution of the evaporating pipe inevitably results in the relative change in the flow of the remaining holes. Because the flow pressure is smaller and smaller in the external channel of the flame tube, the pressure difference between the two sides of the front hole is larger than that between the two sides of the rear hole. Therefore, the flow difference between the front hole and the area method is large. This influence is more evident in the second and fourth rows of holes with the same aperture. As the total flow becomes larger and larger, the pressure difference between the two sides of each row of holes decreases, so the flow of each hole is closer to the area conversion flow. In that fifth and sixth row of holes at the extreme end of the outer channel of the flame tube, the pressure difference in the two rows of holes is relatively small and the change is relatively small compared to other holes so that the flow percentage in the two rows of holes is slightly lower than that of the area conversion and the change of flow distribution is small.

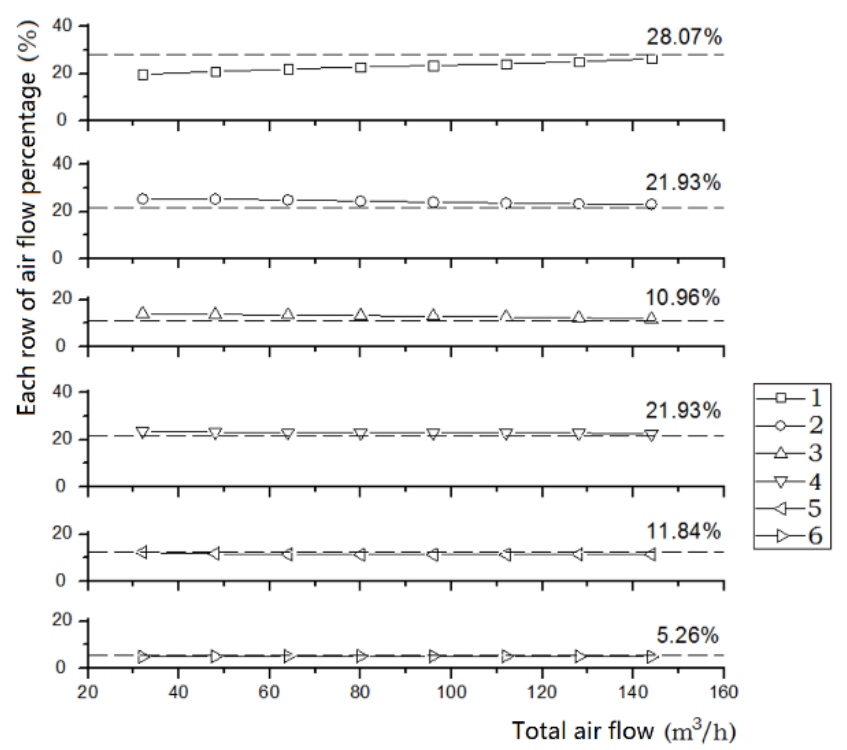

Figure 7. Comparison of flow distribution of area conversion and test measurement

\section{CONCLUSIONS}

(1) Based on the principle of the plugging method, the flow distribution of the small backflow combustor is measured by using thermistor. The test result is proved to be reliable according to the total flow of each row of holes in the flame tube equal to the total flow at the inlet of the combustor. This test method has little interference with the flow field in the combustor, so it is suitable for the study of small combustor.

(2) For a small jet engine on the order of over $10 \mathrm{~cm}$, an evaporating pipe backflow combustor is designed. By measuring the flow of each airflow channel on the wall of the flame tube, it is shown that the flow distribution of each airflow channel will change with the change of the inlet flow when the inlet flow of the combustor is small, and the flow resistance of the evaporating pipe and the position of the airflow channel on the flame tube have certain influence on the flow distribution. As the inlet flow of the combustor increases, the flow distribution of airflow channel approaches the flow determined by the intake channel area.

\section{ACKNOWLEDGMENT}

Basic scientific research fee project of central colleges and universities (3122015C009); Experimental technological innovation fund (02-14-01); Scientific research startup fund project (2011QD07S).

\section{REFERENCES}

[1] Xia C, Fu X, Wan Z, Huang GP, Chen J. (2013). Research on windmill startingcharacteristics of MTE-D micro turbine engine. Chinese Journal of Aeronautics 26(4): $\quad 858-867 . \quad$ http://dx.doi.org/10.1016/j.cja. 2013.06.003

[2] Rideau JF, Guyader G, Cloarec A. (2008). Microturbo families of turojet engine for missiles and UAV's from the tr60 to the new bypass turpass turbojet engine generation. AIAA 2008-4590

[3] Aly ME, Mohamed KK, Hesham EK. (2016). Theoretical and experimental analysis of a micro turbojet engine's performance. International Journal of Scientific \& Engineering Research 7(1): 404-410.

[4] Ralph TD, Charles CG. (1956). Discharge coefficients for combustor liner air entry holes I-circular holes with parallel flow. NACA TN 3663.

[5] Ralph TD. (1958). Discharge coefficients for combustor liner air entry holes II-flush rectangular holes, Step Louvers, and Scoops. NACA TN 3924.

[6] Camaraza-Medina Y, Khandy NH, Carlson KM, CruzFonticiella OM, García-Morales OF, Reyes-Cabrera D. (2018). Evaluation of condensation heat transfer in aircooled condenser by dominant flow criteria. Mathematical Modelling of Engineering Problems 5(2): 76-82. https://doi.org/10.18280/mmep.050204

[7] Francis UH, Herman M. (1947). Effect of airflow distribution and total pressure loss on performance of one sixth segment of turbojet combustor. NACA-RMSE7K16.

[8] Robert RT, Jack G. (1969). Analysis of total pressure loss and airflow distribution for annular gas turbine combustors. NASA-TN-D-5385. 
[9] Peyrac C, Lefebvre F, Westphal O, Gornet L. (2016). Comparison of fatigue limits obtained on thermoplastic composites from SN curve \& self-heating method. Revue des Composites et des Materiaux Avances 26(1): 115126.

[10] Jin RS. (1988). Aviation gas turbine combustor. Aerospace publishing house, $\mathrm{CHN}$.

[11] Liu X. (2018). Study on the temperature characteristics of phase-change energy storage building materials based on ansys. Chemical Engineering Transactions 66: $385-$ 390. https://doi.org/10.3303/CET1866065

[12] Wang BJ, Chen T, Zhao Y, Peng W, Wang J, Xia JY, Jiang MZ. (2018). Effects of high voltage pulsed electric field on antioxidant activity and extraction of tea polysaccharides for third grade ripe pu'er tea. Chemical Engineering Transactions 64: 319-324. https://doi.org/10.3303/CET1864054 